\title{
A comparative study of noise in supercontinuum light sources for ultra-high resolution optical coherence tomography
}

Maria J. , Sanjuan-Ferrer,; Bravo Gonzalo, Ivan; Bondu, Magalie; Engelsholm, Rasmus Dybbro; Feuchter, Thomas; Moselund, Peter M.; Leick, Lasse; Bang, Ole; Podoleanu, Adrian

\section{Published in:}

Proceedings of SPIE

Link to article, DOI:

$10.1117 / 12.2251500$

Publication date:

2017

Document Version

Publisher's PDF, also known as Version of record

Link back to DTU Orbit

Citation (APA):

Maria J., S-F., Bravo Gonzalo, I., Bondu, M., Engelsholm, R. D., Feuchter, T., Moselund, P. M., Leick, L., Bang, O., \& Podoleanu, A. (2017). A comparative study of noise in supercontinuum light sources for ultra-high resolution optical coherence tomography. In Proceedings of SPIE (Vol. 10056). [100560O] SPIE - International Society for Optical Engineering. Proceedings of SPIE - The International Society for Optical Engineering https://doi.org/10.1117/12.2251500

\section{General rights}

Copyright and moral rights for the publications made accessible in the public portal are retained by the authors and/or other copyright owners and it is a condition of accessing publications that users recognise and abide by the legal requirements associated with these rights.

- Users may download and print one copy of any publication from the public portal for the purpose of private study or research.

- You may not further distribute the material or use it for any profit-making activity or commercial gain

- You may freely distribute the URL identifying the publication in the public portal 


\title{
A comparative study of noise in supercontinuum light sources for ultra-high resolution Optical Coherence Tomography
}

\author{
M. Maria*a, b, I. B. Gonzalo ${ }^{\text {c }}$, M. Bondu ${ }^{\text {a, b }}$, R. D. Engelsholm ${ }^{\text {c }}$, T. Feuchter ${ }^{\text {a }}$, P. M. Moselund ${ }^{\text {a }}$, L. \\ Leick $^{\mathrm{a},} \mathrm{O}$. Bang ${ }^{\mathrm{c}}$ and A. Podoleanu ${ }^{\mathrm{b}}$ \\ ${ }^{a}$ NKT Photonics A/S, Blokken 84, DK-3460 Birkerod, Denmark \\ ${ }^{\mathrm{b}}$ Applied Optics Group, School of Physical Sciences, University of Kent, Canterbury CT2 7NH, \\ United Kingdom \\ ${ }^{c}$ DTU Fotonik, Danmarks Tekniske Universitet, Ørsteds Plads 343, DK-2800 Kongens Lyngby, \\ Denmark
}

Keywords: Optical Coherence Tomography, Supercontinuum, Noise.

\section{INTRODUCTION}

Supercontinuum (SC) light is a well-established technology, which finds applications in several domains ranging from chemistry to material science and imaging systems [1-2]. More specifically, its ultra-wide optical bandwidth and high average power make it an ideal tool for Optical Coherence Tomography (OCT). Over the last 5 years, numerous examples have demonstrated its high potential [3-4] in this context. However, SC light sources present pulse-to-pulse intensity variation that can limit the performance of any OCT system [5] by degrading their signal to noise ratio (SNR). To this goal, we have studied and compared the noise of several SC light sources and evaluated how their noise properties affect the performance of Ultra-High Resolution OCT (UHR-OCT) at $1300 \mathrm{~nm}$. We have measured several SC light sources with different parameters (pulse length, energy, seed repetition rate, etc.).

We illustrate the different noise measurements and their impact on a state of the art UHR-OCT system producing images of skin. The sensitivity of the system was higher than $95 \mathrm{~dB}$, with an axial resolution below $4 \mu \mathrm{m}$.

\section{SETUP}

Fig. 1(a) describes the UHR-OCT system used in this study. It consists in a Michelson interferometer illuminated by an ultra-broadband optical source SC combined with a broadband filter (Super K Gauss - NKT Photonics A/S) providing an optical bandwidth of several hundred $\mathrm{nm}$ around a central wavelength of $1270 \mathrm{~nm}$ at different repetition rate. The interferometer itself contains a broadband directional coupler splitting the light towards both, a reference and a sample arm respectively. The sample arm consists of a reflective collimator (C1), a pair of galvo-scanners (XY) and a scanning lens (OBJ) with a 10× magnification and a focal length of $18 \mathrm{~mm}$ (Thorlabs LSM 02). The reference arm is made of a reflective collimator (C1), a block of glass matching the dispersion of the scanning lens (Thorlabs LSM 02DC), a neutral density filter and a flat mirror (FM). The detection is performed by an ultra-broadband spectrometer with a bandwidth of $400 \mathrm{~nm}$ centered at $1270 \mathrm{~nm}$ (Wasatch Photonics - Cobra 1300). It employs an InGaAs camera operated at a line rate of $40 \mathrm{kHz}$ (Goodrich GL2048L).

Fig.1(b) describes the typical design used for SC generation. Light from a seed laser at $1060 \mathrm{~nm}$ is amplified through fiber based amplification in order to reach typical power of few watts. Then, the light is injected into a highly non-linear fiber (HNLF), generally a photonics crystal fiber (PCF), in order to generate a supercontinuum of wavelengths from $\sim 500$ $\mathrm{nm}$ to $2.4 \mu \mathrm{m}$. An example of spectrum from a SC is presented in Fig. 1(c).

As a comparison, we propose to investigate the use of different SC sources for UHR-OCT at a central wavelength of $1300 \mathrm{~nm}$. Table 1 presents the seed laser parameters used to generate 3 different SCs which are then used to illuminate the UHR-OCT setup. Two SCs are based on a seed pulse of 7 ps and a repetition rate of 80 or $320 \mathrm{MHz}$, a third SC is based on a longer seed pulse of 27 ps but with a lower repetition rate of $20 \mathrm{MHz}$.

Design and Quality for Biomedical Technologies X, edited by Ramesh Raghavachari, Rongguang Liang, Proc. of SPIE Vol. 10056, 1005600 - (c) 2017 SPIE · CCC code: 1605-7422/17/\$18 - doi: 10.1117/12.2251500 


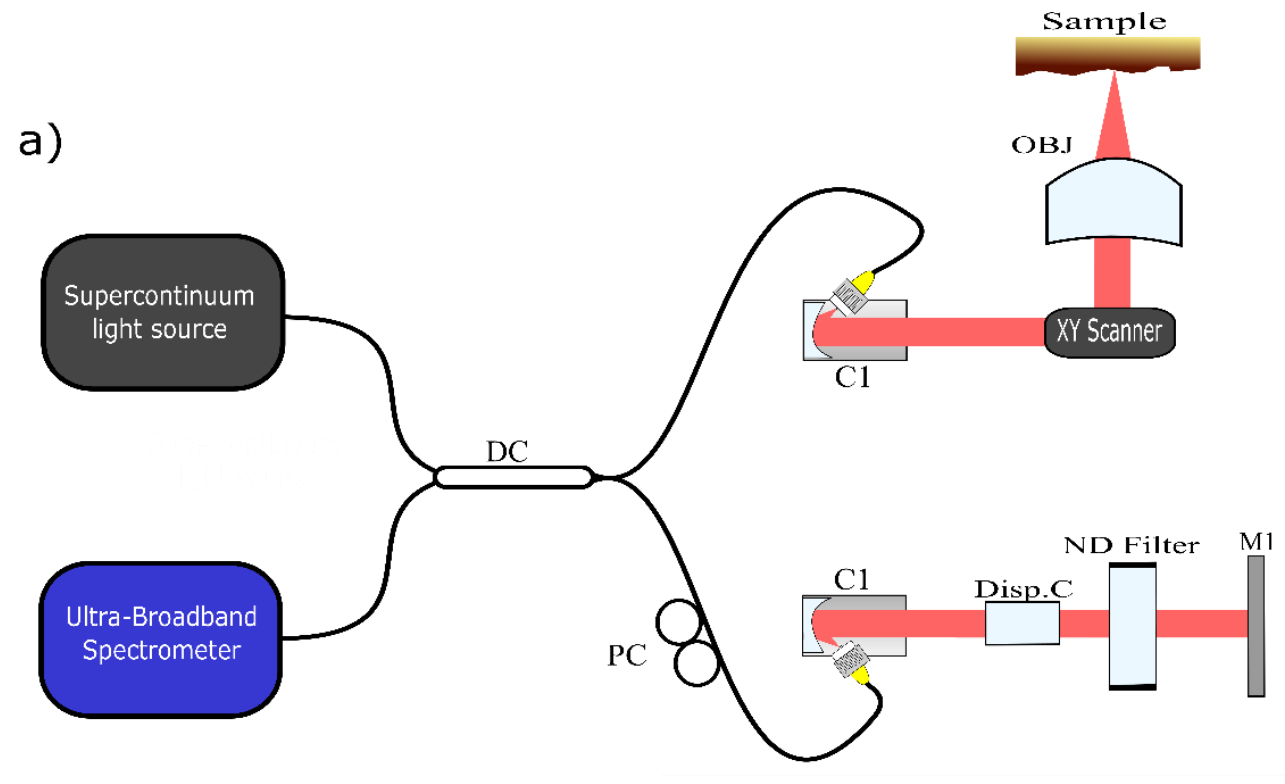

\section{b)}
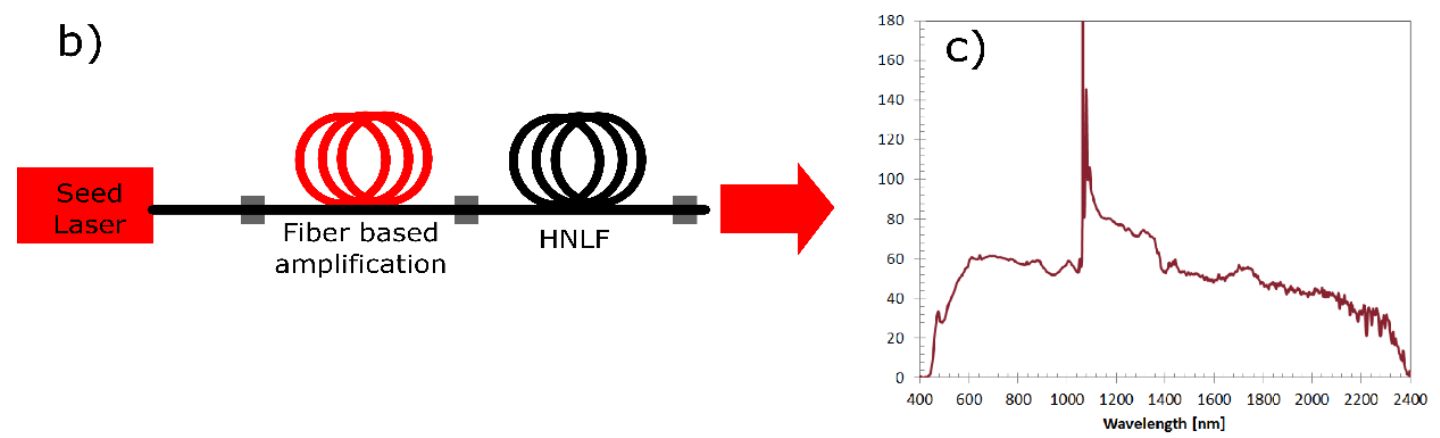

Fig. 1: System description: (a) Schematic of the UHR-OCT system with DC: directional coupler, C1: collimators, PC: polarization controller, XY scanner a pair of galvo-scanners, OBJ: objective, Disp.C: dispersion compensation block, ND Filter: neutral density filter, M1: flat mirror. (b) Typical SC design. (c) Example of SC output spectrum.

\begin{tabular}{|c|c|c|}
\hline Supercontinuum ID & $\begin{array}{c}\text { Seed Pulse Length } \\
\text { (ps) }\end{array}$ & $\begin{array}{c}\text { Seed Repetition } \\
\text { Rate ( MHz) }\end{array}$ \\
\hline Super K Extreme & 7 & 80 \\
\hline Super K Extreme & 7 & 320 \\
\hline SC & 27 & 20 \\
\hline
\end{tabular}

Table. 1: SC's seed laser parameter for comparison.

\section{RESULTS}

The first measurement presented is the sensitivity observed when using the 3 SC sources previously described. The sensitivity is obtained by measuring the signal to noise ratio obtained when a neutral density filter and a flat mirror are used in the sample arm of the UHR-OCT set-up. In order to describe the system specifications under similar conditions to those used in imaging, a power of $4 \mathrm{~mW}$ is used in the sample arm and in order to avoid the saturation of the camera due to the reflection of the mirror in the sample arm, a neutral density filter is used with an optical density of 2 (OD=2). Fig. 2(a-c) shows the sensitivity decays with depth for the $3 \mathrm{SC}$ sources. All three SCs present a sensitivity higher than $85 \mathrm{~dB}$ for a depth up to $1 \mathrm{~mm}$. However, it is noticeable that the larger the repetition rate, the higher the sensitivity. This may be explained based on the fact that by increasing the repetition rate, the relative intensity noise from the optical source is 
reduced. The overall drop of sensitivity over the depth range is mainly due to the spectrometer itself and not to the source, this effect can be seen in Fig. 2(c) where the drop profiles of sensitivity with depth is similar to the two SC sources.
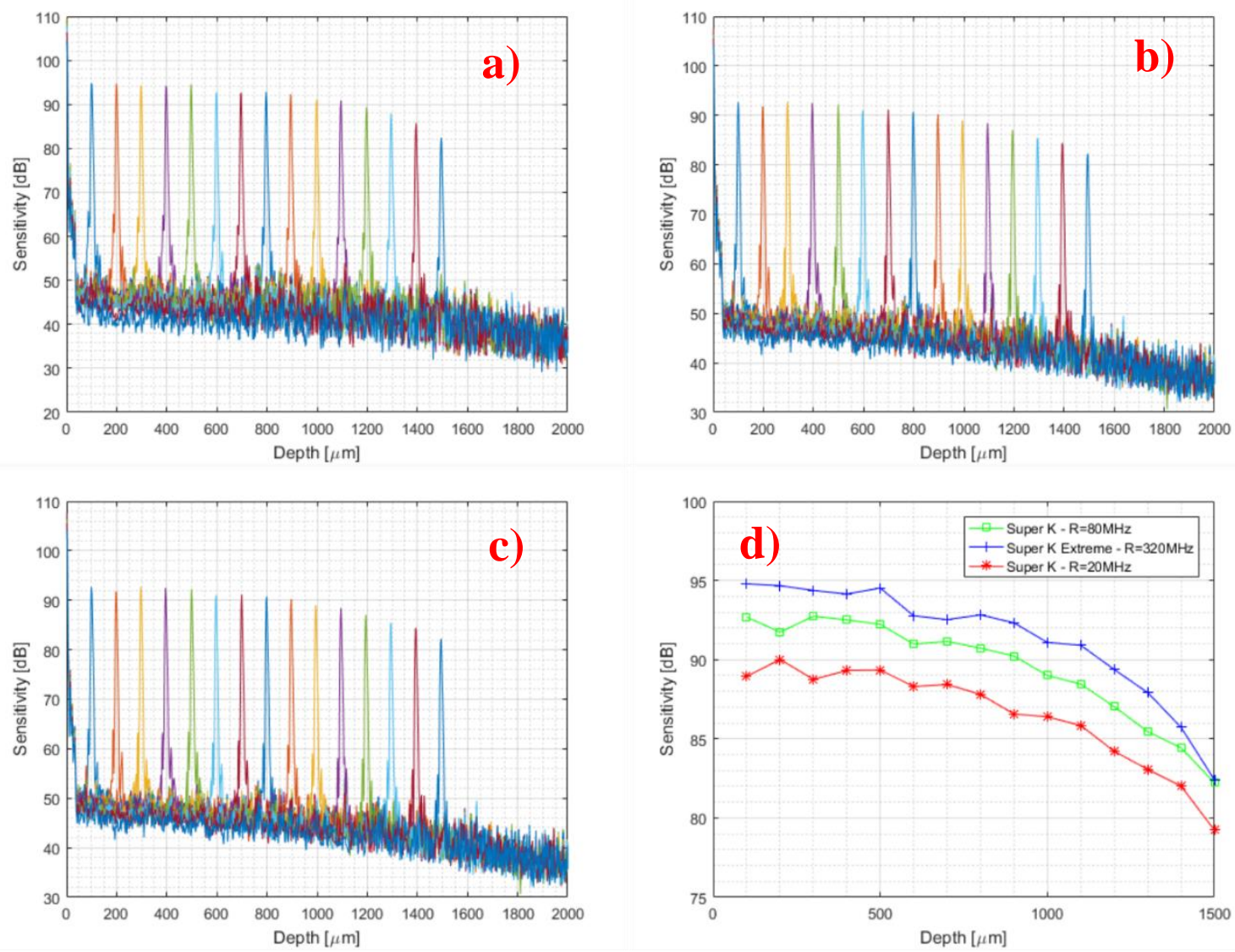

Fig.2: Sensitivity measurements of the three SC sources: (a) Sensitivity peak for Super K Extreme $-\mathrm{R}=320 \mathrm{MHz}$. (b) Sensitivity peak for Super K Extreme $-\mathrm{R}=80 \mathrm{MHz}$. (c) Sensitivity peak for the SC with R = $20 \mathrm{MHz}$. (d) Sensitivity curves for all SC.

The sensitivity profiles in Fig. 2(d) impact the quality of images differently, as can be noticed on the images shown in Fig. 3 and Fig. 4, of B-scans measured from a volunteer skin and finger nail. An optical power of $4 \mathrm{~mW}$ is applied on the sample. The sets of images have been recorded at times separated by several hours. This is explaining why the images do no display exact the same part of tissue. The images obtained using the higher repetition rate SC exhibit a darker background in comparison with the images produced with the lower repetition rate SC source. The background noise affects the contrast and hence, the overall image quality. 

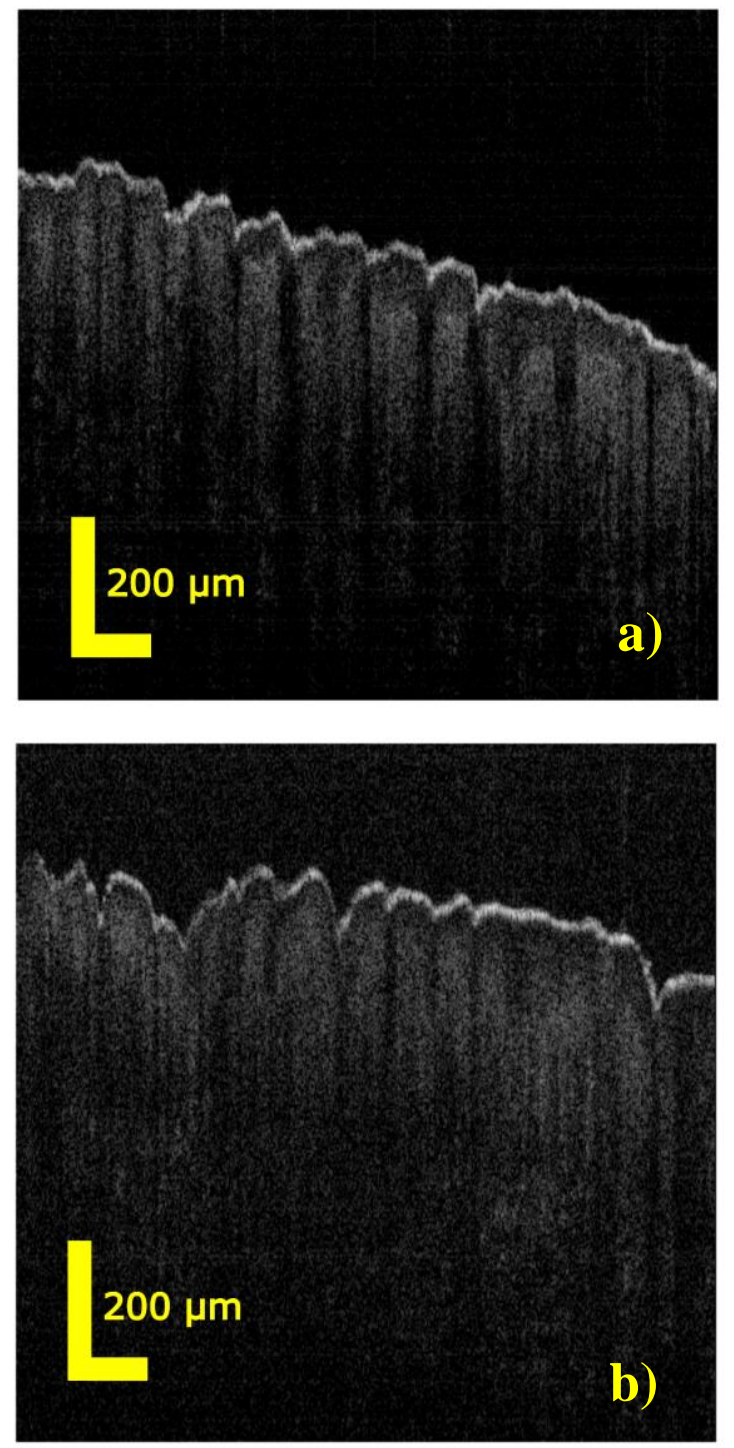

Fig. 3: OCT B-scans of human skin taken in-vivo from a volunteer's finger. (a) Super K Extreme $-\mathrm{R}=320 \mathrm{MHz}$. (b) Supercontinuum $-\mathrm{R}=20 \mathrm{MHz}$. 

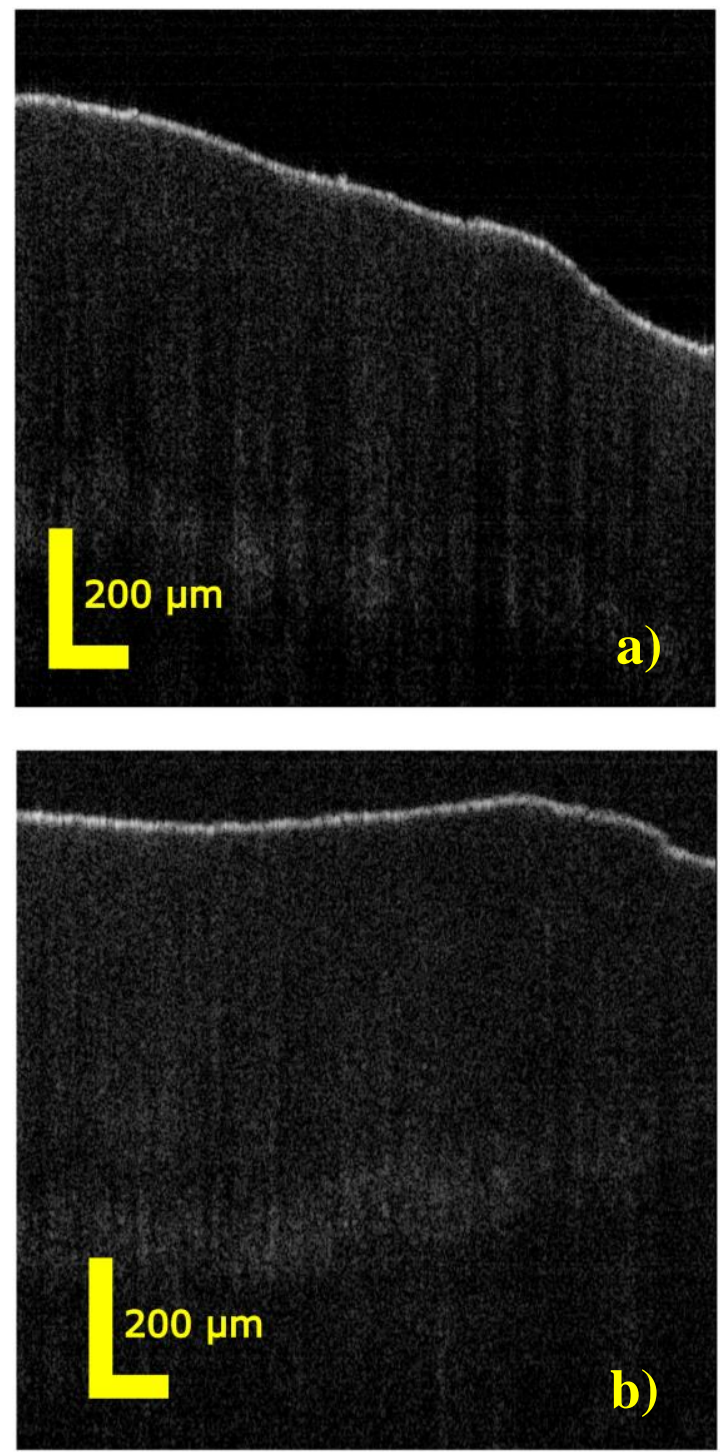

Fig. 4: OCT B-scans of human nail taken in-vivo from a volunteer's finger. (a) Super K Extreme $-\mathrm{R}=320 \mathrm{MHz}$. (b) Supercontinuum $-\mathrm{R}=20 \mathrm{MHz}$.

\section{CONCLUSION}

In conclusion, we have investigated the effect of the laser seed pulse repetition rate on the noise of a SC for UHROCT at $1300 \mathrm{~nm}$. Differences up to $5 \mathrm{~dB}$ on the OCT sensitivity are observed when the repetition rate is varied from 20 $\mathrm{MHz}$ to $320 \mathrm{MHz}$. Images of human skin and finger nail are acquired in-vivo and present a clear difference in background darkness which confirm the sensitivity differences. 


\section{ACKNOWLEDGMENTS}

MM, TF, PM, LL and AP acknowledge support from the European Industrial Doctorate UBAPHODESA, FP7-PEOPLE2013-ITN 607627. IB, RE and OB acknowledge the support of the Innovationsfonden SHAPEOCT. AP acknowledge the support of ERC (http://erc.europa.eu) COGATIMABIO 249889. AP is also supported by the NIHR Biomedical Research Centre at Moorfields Eye Hospital NHS Foundation Trust and the UCL Institute of Ophthalmology and the Royal Society Wolfson Research Merit Award.

\section{REFERENCES}

1. S. Liukaityte, M. Lequime, M. Zerrad, T. Begou, and C. Amra," Broadband spectral transmittance measurements of complex thin-film filters with optical densities of up to 12," Opt. Express. 40 (14), 3225-3228 (2015).

2. F. LaRocca, D. Nankivil, S. Farsiu, and J. A. Izatt," True color scanning laser ophthalmoscopy and optical coherence tomography handheld probe,", Biomed. Opt. Express. 5 (9), 3204-3216 (2014).

3. X. Shu, M. Bondu, B. Dong, A. Podoleanu, L. Leick, and H. F. Zhang," Single all-fiber-based nanosecond-pulsed supercontinuum source for multispectral photoacoustic microscopy and optical coherence tomography," Opt. Letters. 41 (12), 2743-2746 (2016).

4. S. Chen; X. Shu; J. Yi; A. Fawzi; H. F. Zhang," Dual-band optical coherence tomography using a single supercontinuum laser source," J. Biomed. Opt. 21 (6), 066013 (2016).5. K. L. Corwin, N. R. Newbury, J. M. Dudley, S. Coen, S. A. Diddams, K. Weber, and R. S. Windeler," Fundamental Noise Limitations to Supercontinuum Generation in Microstructure Fiber,” Phys. Rev. Lett. 90, 113904 (2003). 